\title{
1954 Sask. Christmas Bird Count
}

\section{IMPORTANT! READ CAREFULLY:}

Fill out this report for the best one day between Dec. 20 and Jan. 3. Underline all species seen on that one day.

e.g. Snow Bunting, 55

Then circle all other species seen on other days during the period from Dec. 20 to Jan. 3, and mark the date seen.

$$
\text { e.g. Hairy Woodpecker }
$$

Dec. 29

Sask., (describe area covered:

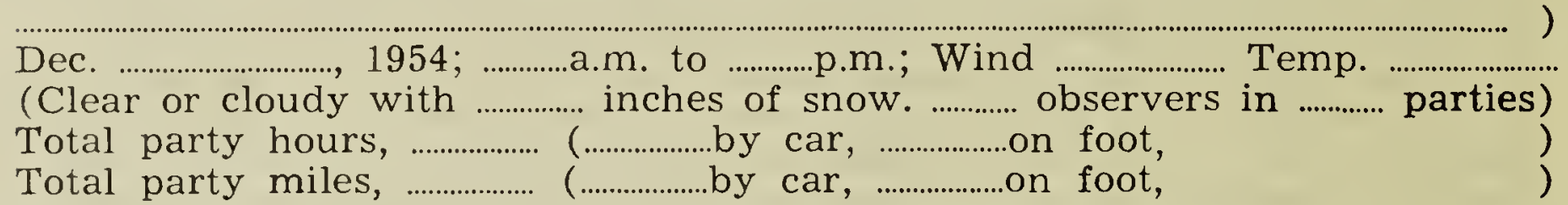

\section{Mallard}

\section{Lesser Scaup}

American Goldeneye

Goshawk

Amer. rough-legged Hawk

Marsh Hawk

Golden Eagle

Bald Eagle

Prairie Falcon

Pigeon Hawk

Spruce Grouse

Ruffed Grouse

Willow Ptarmigan

Sharp-tailed Grouse

Hungarian Partridge

Chukar Partridge

Ring-necked Pheasant

Great Horned Owl

Snowy Owl

Hawk Owl

Long-eared Owl

Short-eared Owl

Richardson's Owl

Saw-whet Owl

Yellow-shafted Flicker

Pileated Woodpecker

Hairy Woodpecker

Downy Woodpecker

Arctic three-toed Woodpecker

Amer. three-toed Woodpecker

Horned Lark

Canada Jay

Blue Jay

Magpie

Raven

American Crow

Comments (re circumstances of identification of rarer species, etc.)
Black-capped Chickadee

Hudsonian Chickadee

White-breasted Nuthatch

Red-breasted Nuthatch

Brown Creeper

American Robin

Golden-crowned Kinglet

Bohemian Waxwing

Cedar Waxwing

Northern Shrike

European Starling

English Sparrow

Western Meadowlark

Red-winged Blackbird

Brewer's Blackbird

Bronzed Grackle

Evening Grosbeak

Pine Grosbeak

Gray-crowned Rosy Finch

Hepburn's Rosy Finch

Hoary Redpoll

Common Redpoll

Red Crossbill

White-winged Crossbill

Vesper Sparrow

Slate-colored Junco

Tree Sparrow

Song Sparrow

Lapland Longspur

Snow Bunting 